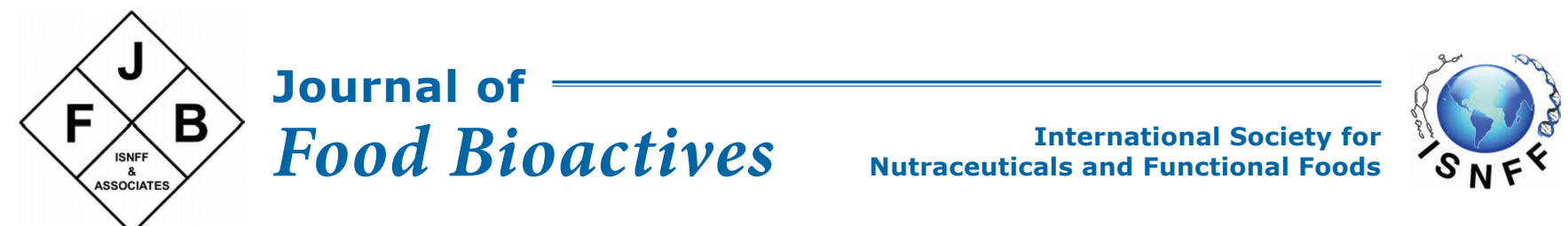

Original Research

J. Food Bioact. 2021;14:60-74

\title{
Characterization and profiling of polyphenolics of Brassica microgreens by LC-HRMS/MS and the effect under LED light
}

\author{
Oday Alrifai ${ }^{\mathrm{a}, \mathrm{b}}$, Lili Mats ${ }^{\mathrm{a}}$, Ronghua Liu ${ }^{\mathrm{a}}$, Honghui Zhua ${ }^{\mathrm{a}}$ Xiuming $\mathrm{Hao}^{\mathrm{c}}$, \\ Massimo F. Marcone ${ }^{\mathrm{b}}$ and Rong Tsao ${ }^{\mathrm{a}^{*}}$
}

\begin{abstract}
${ }^{a}$ Guelph Research \& Development Center, Agriculture and Agri-Food Canada, 93 Stone Road West, Guelph, Ontario, Canada, N1G 5C9 bDepartment of Food Science, Ontario Agricultural College, University of Guelph, Guelph, Ontario, Canada, N1G 2W1

${ }^{\circ}$ Harrow Research \& Development Center, Agriculture and Agri-Food Canada, 2585 County Road 20, Harrow, Ontario, Canada, N0R 1G0 *Corresponding author: Rong Tsao, Guelph Research \& Development Center, Agriculture and Agri-Food Canada, 93 Stone Road West, Guelph, Ontario, Canada, N1G 5C9. E-mail: rong.cao@canada.ca
\end{abstract}

DOI: $10.31665 /$ JFB. 2021.14268

Received: May 13, 2021; Revised received \& accepted: June 15, 2021

Citation: Alrifai, O., Mats, L., Liu, R., Zhu, H., Hao, X., Marcone, M.F., and Tsao, R. (2021). Characterization and profiling of polyphenolics of Brassica microgreens by LC-HRMS/MS and the effect under LED light. J. Food Bioact. 14: 60-74.

\begin{abstract}
An untargeted approach to profiling of polyphenolics of Brassicaceae microgreens was employed to characterize the phenolic composition in microgreens grown under 8 different treatments of combined amber $(590 \mathrm{~nm})$, blue $(455 \mathrm{~nm})$, and red (655 nm) LED, using full MS and HRMS/MS-ESI. Hydroxycinnamic acid (HCA) derivatives predominated the pool of phenolics in the microgreens, followed by free phenolic acids and flavonol glycosides/ acylglycosides, with most of the HCA derivatives existing as malate esters. Most HCA malates in mustard (Barbarossa) and all HCA malates in mizuna (red kingdom)/ radish (red Rambo, organic) were significantly decreased under most treatments, whereas all malates were overall increased under combined lighting in radish (red Rambo), mustard (Garnet Giant), mizuna (organic), Pac choi (red Pac) and mustard (Scarlet Frills). The present study demonstrated that amber in combination with blue and red LED contributed to the altered phenolic profile and increase and/or decrease in quantity of certain phenolic compounds, particularly the HCA malates.
\end{abstract}

Keywords: Amber light; Polyphenolics; Phytochemicals; Light-emitting diodes; Microgreens; LC-HRMS/MS-ESI.

1. Introduction

Polyphenolics are secondary metabolites widely distributed as aglycones or their glycosides or acylglycosides in plants. A wide range of research has been conducted on dietary polyphenolics mainly due to their roles in human health (Zhang and Tsao, 2016). Brassicaceae (or Brassica, Crucifers) vegetables are the most consumed globally with several reports highlighting their importance for preventing cardiovascular diseases and certain cancers due to their antioxidant properties (Lin et al., 2011). Extensive research has shown that major polyphenolics in Brassica vegetables exist as glycosides or acylglycosides of quercetin (Qn), kaempferol (Km) and isorhamnetin (Iso) with various sug- ar moieties occurring as mono-, di-, tri-, tetra- and penta-glucosides. The acylated flavonoids are mainly with hydroxycinnamic acids (HCA), particularly coumaric, caffeic, sinapic and ferulic acids (Olsen et al., 2009; Sun et al., 2013). Recent review papers have compiled numerous studies pointing towards the neuroprotective and anti-carcinogenic effects of flavonoids, suggesting a diet containing these compounds may be part of the treatment for Alzheimer's disease and several cancers (Kim and Park, 2021; Ponte et al., 2021).

Optimal lighting for microgreens production is a growing topic as energy-efficient LED technology has advanced significantly and is now equipped in plant factories together with advanced greenhouse systems and hybrid lighting (Alrifai et al., 2019; Kyri- 
acou, et al., 2019). Red light (RL) and blue light (BL) wavebands are deemed the most efficient for driving metabolic changes in plants, including phytochemical biosynthesis for defense-related activities, compared to other components of the visible light spectrum. These lights are absorbed by chlorophyll photosynthetic pigments responsible for accumulating metabolites of polyphenols, carotenoids and glucosinolates (Alrifai et al., 2019). We previously reported on the effects of amber LED on total phenolic contents and total antioxidant activities, and discussed the need to identify further information, particularly the phenolic composition, on the yellow-orange (mid-point amber light at $590 \mathrm{~nm}$ ) light range to differentiate from commonly reported effects in the broad 500-600 nm green light range (Alrifai et al., 2020; Alrifai et al., 2021).

In the present paper, various LED treatments of combined $\mathrm{AL}, \mathrm{RL}$ and $\mathrm{BL}$ were used to grow eight microgreens of Brassica vegetables to understand the response of individual polyphenolic compounds. Our previous report analyzed total contents of overall polyphenolics, including its sub-groups, and therefore the current study analyzes the contributions of these individual polyphenolics in the overall pool and their accumulation under the LED lights (Alrifai et al., 2020). This is the first study of its kind to analyze the accumulation of individual phenolics under various combinations of amber, red and blue LED in Brassica microgreens. The methods and results will better help the understanding of LED-regulated biosynthesis of these individual health-promoting polyphenolics. Although phytochemical profiles have been reported for mature vegetables of Brassica species, detection of these polyphenolics in microgreens grown under amber $(590 \mathrm{~nm})$ light is reported here for the first time.

\section{Materials and methods}

\subsection{Plant materials, chemical reagents and growth chamber lighting}

Eight varieties of Brassica microgreens, including 2 mizunas [organic and red kingdom (Brassica rapa var. Japonica), MO, MR]; Pac choi (Brassica rapa var. Chinensis), PC; 2 radishes [red Rambo and red Rambo organic (Raphanus sativus), RR, RO], and 3 mustards [Scarlet Frills, Barbarossa and Garnet Giant (Brassica juncea), MSF, MB, MG] were grown at the Harrow Research \& Development Centre, Agriculture and Agri-Food Canada (Harrow, Ontario, Canada) similar to our previous report (Alrifai et al., 2020). Seeds of microgreens purchased from Johnny's Selected Seeds (Winslow, ME, USA) were sown in $100 \%$ Canadian Sphagnum Peat Moss ( $\mathrm{pH}$ 6-6.2, 1,400 ms/M, average quantity of nutrient (ppm) N, 110; P, 32; K, 170; and other microelements $\mathrm{Ca}, \mathrm{Mg}$, Fe, S, Mn, ASB Greenworld Ltd., Mount Elgin, ON, Canada) for germination. Trays were submerged in fertilizer and subsequently moved into a germinating room (24 ${ }^{\circ} \mathrm{C}$; $90 \%$ relative humidity $(\mathrm{RH}) ; 16 \mathrm{~h}$ photoperiod). General maintenance was consistent (i.e. water sprayed, irrigated and trays rotated). Seeds were germinated for $2-3 \mathrm{~d}$, followed by 13-14 d growth period in the chambers. Microgreens were harvested after 15-16 d. Upon first sign of germination, the plantlets were moved to the chambers and were grown until harvest under eight treatments ( 2 treatments/chamber; $16{ }^{\circ} \mathrm{C} ; 70 \% \mathrm{RH} ; 16$ $\mathrm{h}$ photoperiod). Each growth chamber was equipped with amber $(\mathrm{A}, 590 \mathrm{~nm})$, blue $(\mathrm{B}, 455 \mathrm{~nm})$ and red $(\mathrm{R}, 660 \mathrm{~nm})$ LED in different ratios (\%): 4.73A:20.52B:74.36R; 6.74A:22.68B:70.25R; 9.51A:24.13B:65.91R; 12.02A:26.26B:61.14R; 4,12.57A:44.31 B:42.39R; 14.53A:30.18B:51.82R; 18.45A:33.51B:47.48R; and
39.46A:58.94B:0.57R. All microgreens were grown in triplicate over three separate trials. Microgreens were harvested at their base, packed in air-tight plastic bags and stored in $-80{ }^{\circ} \mathrm{C}$ and then lyophilized for extraction and chromatographic analyses. Details related to sample processing and extraction and chamber cabinet settings were similar to that reported in our previous papers (Alrifai et al., 2020; Alrifai et al., 2021). Single extractions were carried out for each sample for a total of 3 replicates per variety. $\mathrm{HPLC}$ grade methanol $(\mathrm{MeOH})$, formic acid and acetonitrile $(\mathrm{ACN})$ were purchased from Caledon Laboratories (Georgetown, ON, Canada). All chemical reagents used were of analytical grade.

\subsection{Identification of phenolics by LC-HRMS/MS}

An untargeted approach to profiling combining full MS and MSMS methods was used to obtain reliable peak area and fragmentation data in one run. Pooled quality control (QC) samples for each microgreen were created by combining $10 \mu \mathrm{L}$ of each sample. Samples were randomized before analysis and QC samples were periodically inserted into sequence and analyzed in DDMS2 mode (Top $\mathrm{N}=15$ ) with NCE set at 30 . Analysis was carried out in negative ionization mode to ionize polyphenolic analytes in acidified solvent. LC-HRMS/MS analysis was performed using a Thermo ${ }^{\circledR}$ Scientific Q-Exactive ${ }^{\mathrm{TM}}$ Orbitrap mass spectrometer equipped with a Vanquish ${ }^{\mathrm{TM}}$ Flex Binary UPLC System (Waltham, MA, USA). Data were acquired using Thermo Scientific ${ }^{\mathrm{TM}}$ Xcalibur $^{\mathrm{TM}} 4.2$ software and Thermo Scientific ${ }^{\mathrm{TM}}$ Standard Integration Software. The chromatographic separation was performed on a Kinetex XB-C18 100A HPLC column $(100 \times 4.6 \mathrm{~mm}, 2.6$ $\mu \mathrm{m}$, Phenomenex Inc., Torrance, CA, USA). The binary mobile phase consisted of solvent $\mathrm{A}\left(99.9 \% \mathrm{H}_{2} \mathrm{O} / 0.1 \%\right.$ formic acid, $\left.\mathrm{v} / \mathrm{v}\right)$ and solvent $\mathrm{B}(94.9 \% \mathrm{MeOH} / 5 \% \mathrm{ACN} / 0.1 \%$ formic acid, $\mathrm{v} / \mathrm{v} / \mathrm{v})$. The following solvent gradient was used: $0-5 \mathrm{~min}, 0 \%$ to $12 \% \mathrm{~B}$; $5-15 \mathrm{~min}, 12 \%$ to $23 \% \mathrm{~B} ; 15-30 \mathrm{~min}, 23 \%$ to $50 \% \mathrm{~B} ; 30-40 \mathrm{~min}$, $50 \%$ to $80 \% \mathrm{~B} ; 40-42 \mathrm{~min}, 80 \%$ to $100 \% \mathrm{~B} ; 42-45 \mathrm{~min}, 100 \%$ B; $45-46 \mathrm{~min}, 100 \%$ to $0 \% \mathrm{~B}$; $46-52 \mathrm{~min}, 0 \% \mathrm{~B}$. The column compartment temperature was held at $40{ }^{\circ} \mathrm{C}$ and the flow rate was set to $0.700 \mathrm{~mL} / \mathrm{min}, 1 \mu \mathrm{L}$ injections for all sample extracts and either 1 or $5 \mu \mathrm{L}$ for the QC samples. Peaks were monitored at $280,320,360$ and $520 \mathrm{~nm}$ with a diode array detector. MS data was collected in negative ionization mode (spray voltage $=2.8$ $\mathrm{kV}$ ) with scan range set to $90-1,300 \mathrm{~m} / \mathrm{z}$. Data was visualized and analysed using Thermo FreeStyle ${ }^{\mathrm{TM}} 1.6$ software. All compounds were identified by matching the retention time (RT) and MS/MS-MS fragmentation with the in-house database of phenolic standards and that of the literature. Since the predominant phenolics were HCA esters of different organic acids whose standards are not commercially available, the effect of LED light on the quantity of the phenolic compounds detected in this study was evaluated using the ion counts of the peak of extracted ion chromatograms (XIC).

\subsection{Statistical Analysis}

Peak area (ion counts) averages of XIC for the compound of interest were used for one-way ANOVA followed by Dunnett's post hoc test for all LED light treatments and microgreens to determine the differences against control $(\mathrm{p}<0.05)$ using IBM SPSS $\AA$ software for Windows version 25.0 (IBM corporation, Armonk, NY, USA). Contents were expressed as mean \pm SD of triplicate extractions. 


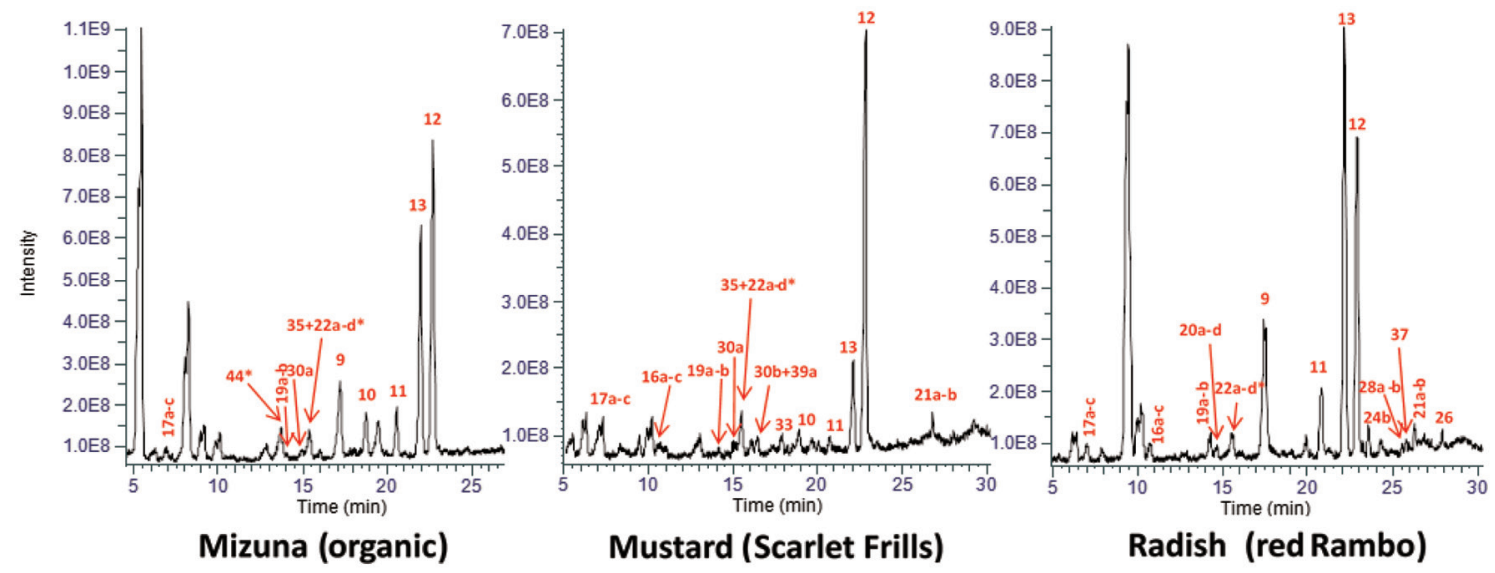

Figure 1. Peak area averages of the extracted ion chromatograms (XIC) of polyphenolic extracts of representative Brassica microgreens [B. rapa (mizuna), $B$. juncea (mustard) and R. sativus (radish)]. The detected polyphenolics are identified according to their fragmentation patterns and retention times, and their content levels are generally identified with a larger intensity. ${ }^{*}$, other non-polyphenolic compounds eluting with detected polyphenolics; quercetin (Qn); kaempferol (Km); caffeoyl malate, 9; hydroxyferuloyl malate, 10; coumaroyl malate, 11; sinapoyl malate, 12; feruloyl malate, 13; salicylic acid glucoside, 16a/b/c; dihydroxybenzoic acid glucoside, 17a/b/c; feruloyl glucoside, 19a/b; sinapoyl gentiobioside, 20a/b/c/d; disinapoyl gentiobioside, 21a/b; sinapoyl glucoside, 22a/b/c/d; Km 3-diglucoside, 24b; Km 3,7-dirhamnoside, 26; Km glucoside rhamnoside, 28a/b; Km hydroxyferuloyl diglucoside glucoside, 30a; qn feruloyl diglucoside glucoside, 30b; km sinapoyl diglucoside glucoside, 33; Km caffeoyl-diglucoside glucoside, 35; Qn dirhamnoside, 37; Qn sinapoyl diglucoside glucoside, 39a; Qn caffeoyl diglucoside glucoside, 44.

\section{Results and discussion}

\subsection{Identification of polyphenolics by LC-HRMS/MS-ESI from Brassica microgreens}

A representative XIC and major phenolic peaks are shown in Figure 1. The phenolic compounds identified in eight Brassica microgreens along with their parent and fragment ions (order of decreasing intensity) and RT are listed in Table 1. A total of 46 phenolics, including phenolic acids and flavonoids, were positively or tentatively identified. Conjugated derivatives of HCA predominated the majority of phenolics identified in the microgreens, followed by free phenolic acids and flavonol glycosides (Figures 1,2). Several studies reported on the phenolic composition in mature Brassica vegetables, and recently in microgreens of mustard, cabbage and pac choi (Sun et al., 2013; Alrifai et al., 2019). A recent study showed the phenolic acid content accounted for $79 \%$ of the mean total phenolic content in three species of microgreens, followed by flavonol glycosides $(20.7 \%)$ and flavone glycosides $(0.3 \%)$ (Kyriacou et al., 2019), a pattern that is similarly found in the current study. Lower contents of HCA and higher flavonol glycosides were found in three other species of microgreens (Kyriacou et al., 2020). The results in the current study agree with literature data, suggesting these groups of phytochemicals are not only specific to the Brassica microgreens, but light quality had a larger influence on their accumulation.

\subsection{Hydroxycinnamic/benzoic acids and derivatives}

Compounds 1, 2 and 3 were identified as $p$-, $m$ - and $o$-coumaric acid, respectively, with the same deprotonated molecular ion [M$\mathrm{H}]^{-}$of $\mathrm{m} / \mathrm{z} 163.0401$ and the major fragment ion at $\mathrm{m} / \mathrm{z} 119.0501$ (Table 1). The main fragment ion of caffeic acid 6 was $\mathrm{m} / \mathrm{z}$ 135.0451 (neutral loss of $\mathrm{CO}_{2}, 44 \mathrm{amu}$, from $[\mathrm{M}-\mathrm{H}]^{-}$) (Chen et al., 2019; Sinosaki et al., 2020). One study identified the presence of ferulic acid 5 in PC microgreens, although this was not seen in the current study which could imply that under the current combined lighting and photon flux the accumulation of 5 was inhibited (Kyriacou et al., 2020). Accumulation of 5 under blue LED (bLED) was higher compared to red LED (rLED) and white LED (wLED) in another study in B. rapa (Kim et al., 2015). Ferulic acid 5 was only found in microgreens of RR, MO and MR (Table 1). Isomers chlorogenic acid 7 and neochlorogenic acid 8, commonly found in low concentrations in Brassica species, were identified by the same deprotonated molecular ion $[\mathrm{M}-\mathrm{H}]^{-}$of $\mathrm{m} / \mathrm{z} 353.087$ and the major fragment ion at $\mathrm{m} / \mathrm{z} 179.0349\left([\mathrm{M}-\mathrm{H}]^{-}\right.$of 6$)$ formed by McLafferty rearrangement (Wu et al., 2009). In the present study compound 7 was found in all but MG, RR and RO, and 8 was only found in MB. In some microgreens and treatments, two overlapping peaks are seen for chlorogenic acid and its isomer (cryptochlorogenic acid) which could not be separated (Figure 1).

Peaks $9-13$ in Figure 1, i.e., caffeoyl malate $\left([\mathrm{M}-\mathrm{H}]^{-} \mathrm{m} / \mathrm{z}\right.$ 295.0460, 9), hydroxyferuloyl malate $\left([\mathrm{M}-\mathrm{H}]^{-} \mathrm{m} / \mathrm{z} 325.05651\right.$, $10)$, coumaroyl malate $\left([\mathrm{M}-\mathrm{H}]^{-} \mathrm{m} / \mathrm{z} 279.051,11\right)$, sinapoyl malate $\left([\mathrm{M}-\mathrm{H}]^{-} \mathrm{m} / \mathrm{z} 339.0722,12\right)$ and feruloyl malate $\left([\mathrm{M}-\mathrm{H}]^{-} \mathrm{m} / \mathrm{z}\right.$ 309.0616 , 13) were tentatively identified according to literature data and based on their deprotonated ions and their fragments (Table 1) (Harbaum et al., 2007; Oszmiański et al., 2013; Koley et al., 2020; Oulad El Majdoub et al., 2020). These were the most dominant phenolics identified in the microgreens, and were all malate esters of caffeic (6), 5-hydroxyferulic acid, p-coumaric (1), sinapic (4) and ferulic acid (5), respectively, from the characteristic loss of malate (116 amu) (Figure 3). In Brassica, hydroxycinnamoyl esters of malic acid are synthesized by action of sinapoylglucose:malate sinapoyltransferase (SGMS), an enzyme which is capable of transferring the hydroxycinnamoyl moiety from a hydroxycinnamoylglucose ester to a malic acid acceptor (Sullivan, 2009). Sinapoylglucose accumulator 1 (SNG1) gene in Arabidopsis thaliana encodes the enzyme responsible for the accumulation of sinapoyl malate in seeds and leaves (Lehfeldt et al., 2000). For example, SGMS extracted from radish (Raphanus sativus) is a homolog of the Arabidopsis SNG1 gene product and can catalyze sinapoyl-, feruloyl-, caffeoyl- and coumaroyl-glucoside esters to form the corresponding malic acid esters (Sullivan, 2009). Peak ion height 


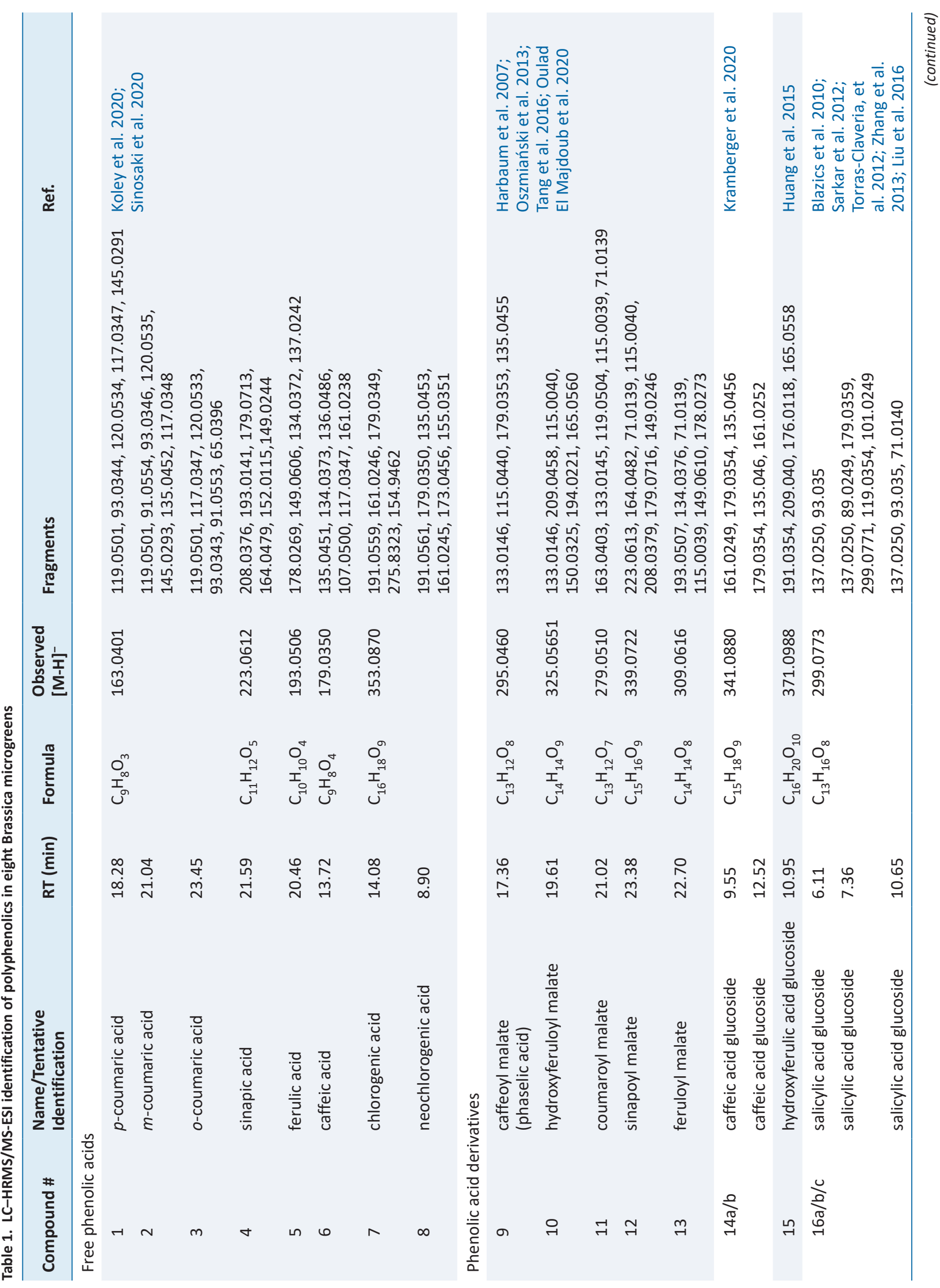


Alrifai et al.

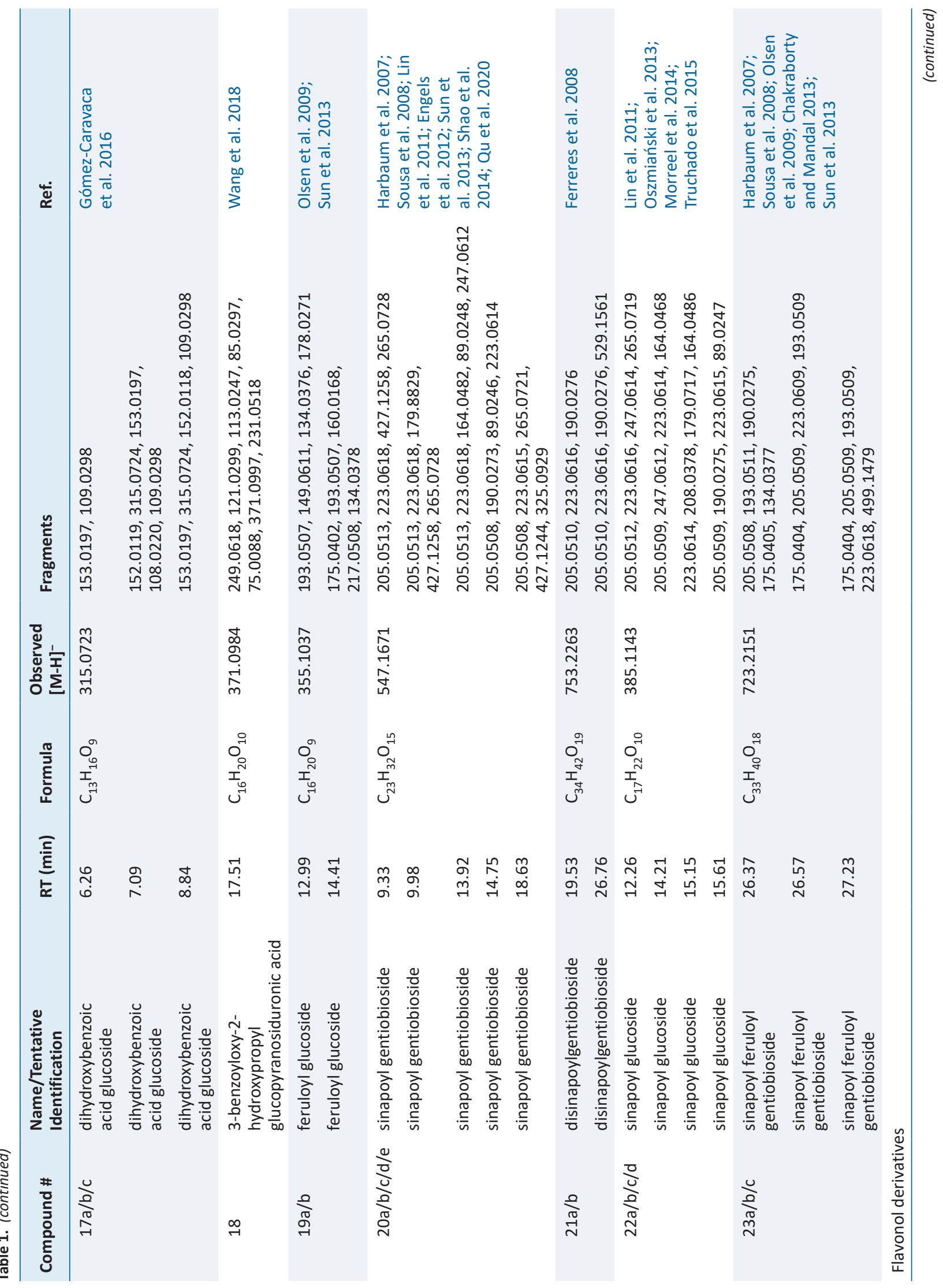




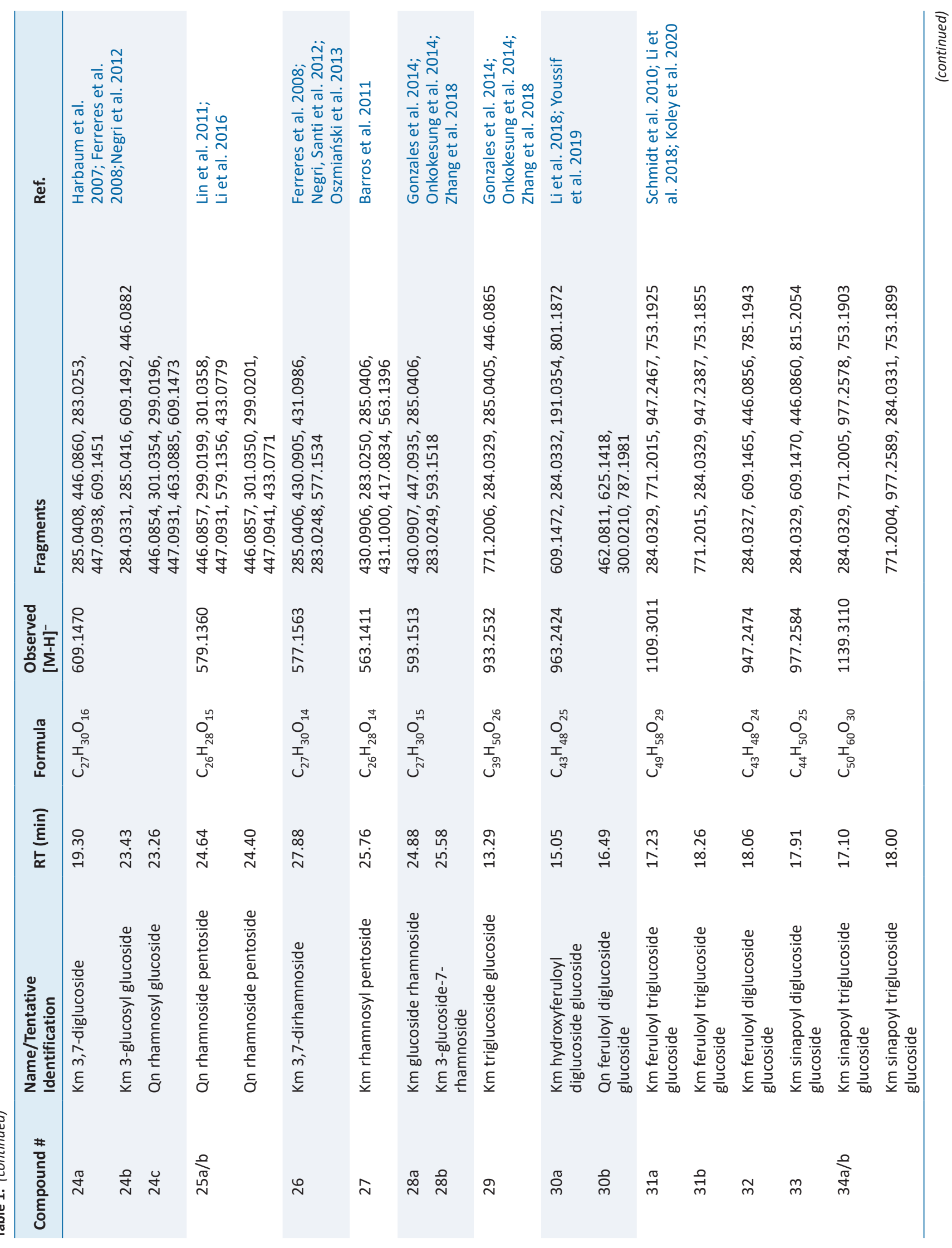




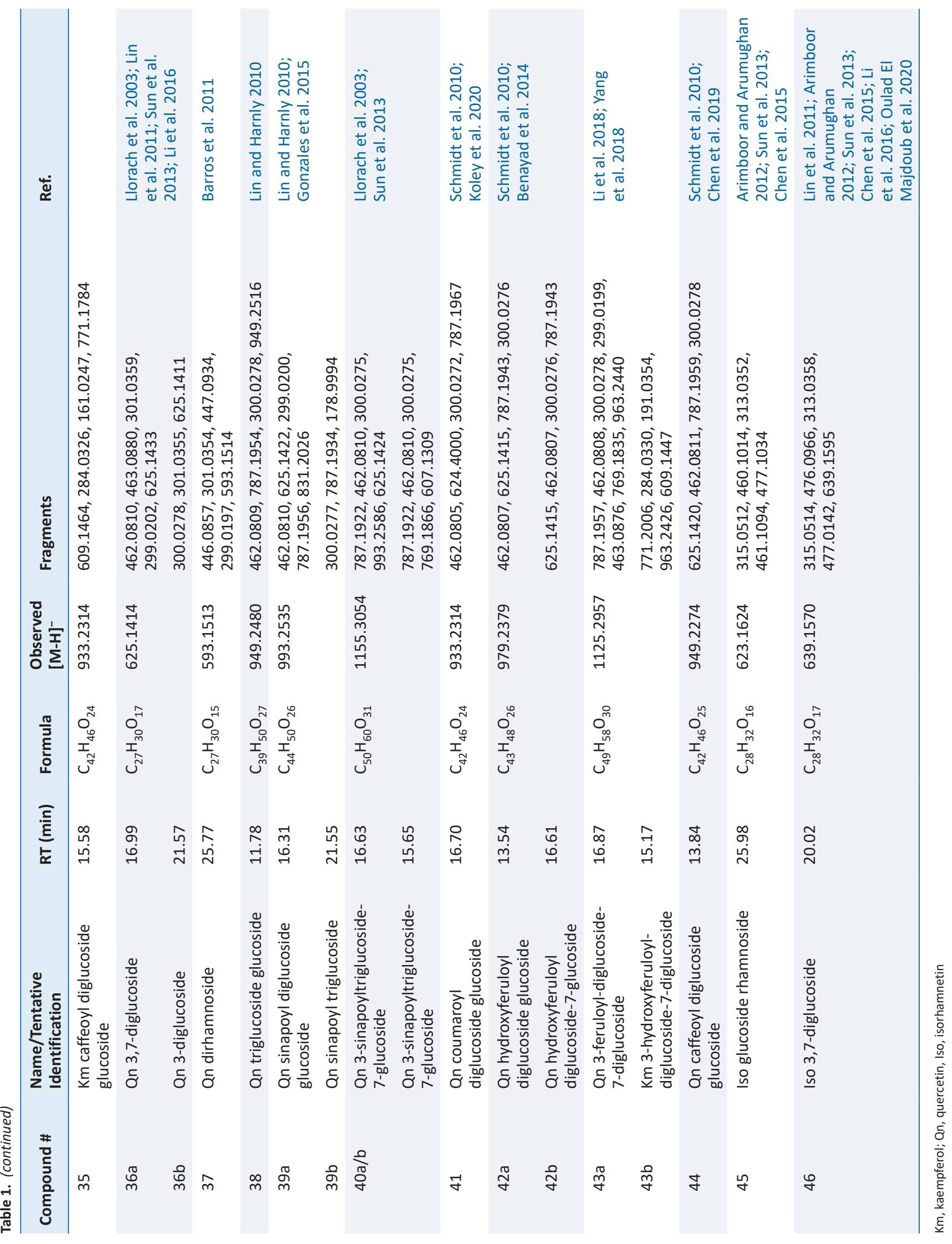




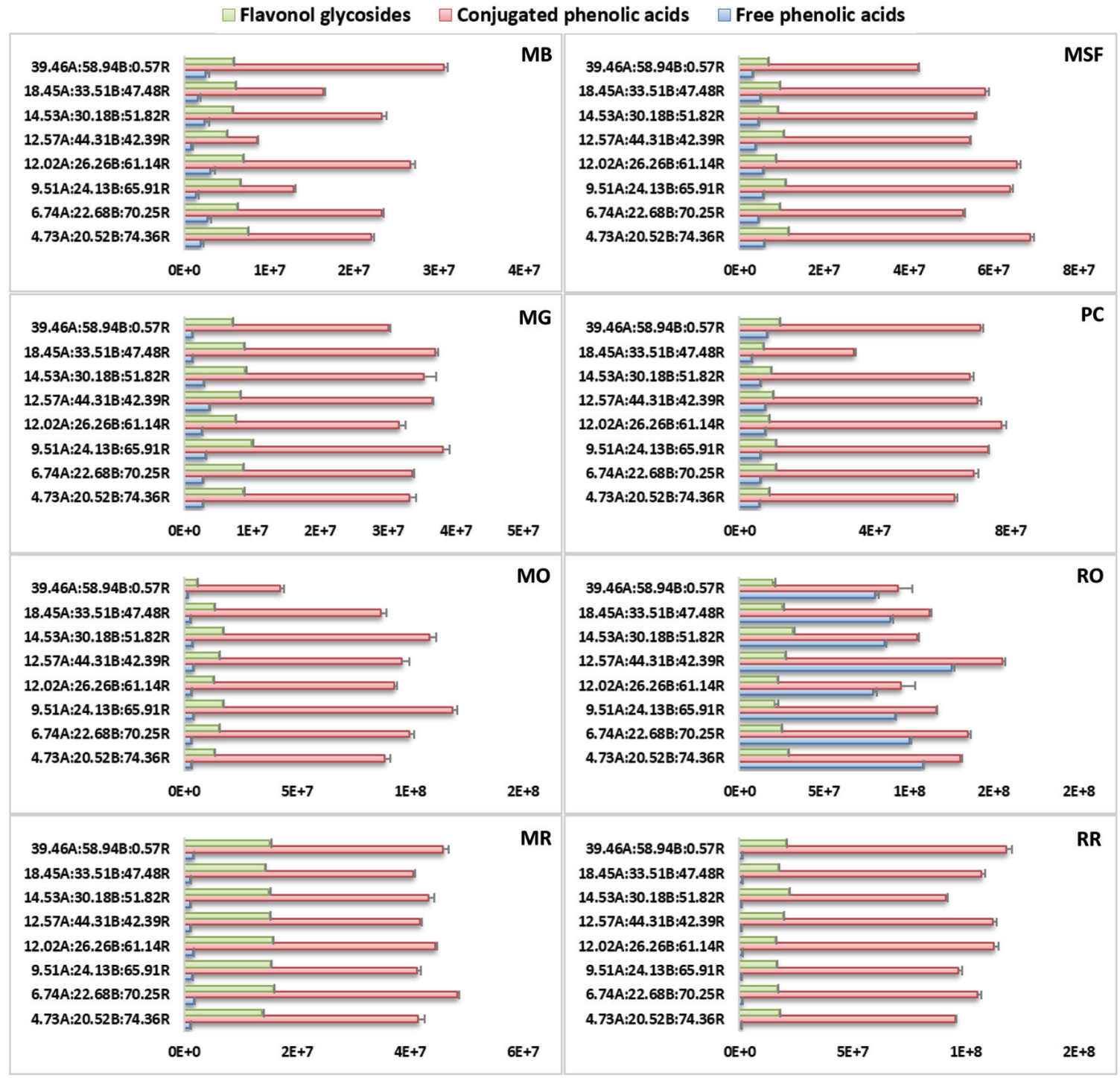

Figure 2. Extracted ion chromatograms (XIC) of three sub-groups of detected polyphenolics (flavonol glycosides/conjugated phenolic acids/free phenolic acids) under each treatment in Brassica microgreens. Control is $4.73 \mathrm{~A}(\mathrm{amber}): 20.52 \mathrm{~B}(\mathrm{blue}): 74.36 \mathrm{R}$ (red) and bars represent the peak area averages $\pm \mathrm{SD}$ of three replicates per microgreen.

was generally the highest for malates, therefore the genes controlling their formation under LED should be further examined to understand the light-regulated gene activity.

Several glucosides or hexosides were indeed also identified. Compound $14 \mathrm{a} / \mathrm{b}$ with $[\mathrm{M}-\mathrm{H}]^{-}$of $\mathrm{m} / \mathrm{z} 341.088$ was identified as caffeic acid glucoside with major fragment of $\mathrm{m} / \mathrm{z} 179.0354(6$, loss of hexosyl, $162 \mathrm{amu}$ ) (Kramberger et al., 2020). Glucosides of hydroxyferulic acid 15 , salicylic acid $16 \mathrm{a} / \mathrm{b} / \mathrm{c}$, dihydroxybenzoic acid $17 \mathrm{a} / \mathrm{b} / \mathrm{c}$, feruloyl $19 \mathrm{a} / \mathrm{b}$ and sinapoyl $22 \mathrm{a} / \mathrm{b} / \mathrm{c} / \mathrm{d}$ were also tentatively identified by matching with literature reports which observed the loss of a glucoside unit (162 amu) from their respective deprotonated molecular ions and the aglycone ions (Table 1) (Olsen et al., 2009; Blazics et al., 2010; Sarkar et al., 2012; Torras-Claveria et al., 2012; Oszmiański et al., 2013; Sun et al., 2013; Zhang et al., 2013; Huang et al., 2015; Truchado et al., 2015; Gómez-Caravaca et al., 2016; Liu et al., 2016; Qu et al., 2020). Salicylic acid is a modulator of plant stress response and is pro- duced in the phenylalanine ammonia lyase/ isochorismate synthase pathway which is responsible for controlling biotic and abiotic factors (Lefevere et al., 2020).

Compound 18 with its deprotonated molecular ion $[\mathrm{M}-\mathrm{H}]^{-}$of $\mathrm{m} / \mathrm{z} 371.0984$ was tentatively identified as 3-benzoyloxy-2-hydroxypropyl glucopyranosiduronic acid according to literature data and fragment of $\mathrm{m} / \mathrm{z} 249.0618$ corresponding to the neutral loss of benzoic acid (122 amu) (Wang et al., 2018). Compound $20 \mathrm{a} / \mathrm{b} / \mathrm{c} / \mathrm{d} / \mathrm{e}$ with $[\mathrm{M}-\mathrm{H}]^{-}$of $\mathrm{m} / \mathrm{z} 547.1671$ showed major fragment of $\mathrm{m} / \mathrm{z} 205.0513$ (loss of gentiobiose, $342 \mathrm{amu}$ ) and m/z 223.0618 (loss of $\mathrm{H}_{2} \mathrm{O}$ from 4), and therefore was tentatively identified as sinapoyl gentiobioside (Table 1) (Lin et al., 2011; Engels et al., 2012; Oszmiański et al., 2013; Morreel et al., 2014; Qu et al., 2020). These compounds were only detected in RR microgreens in the present study. Sinapoyl gentiobioside is relatively abundant in B. oleracea and at least three of its isoforms can be identified in any Brassica species (Sousa et al., 2008; Lin et al., 2011; Shao et 


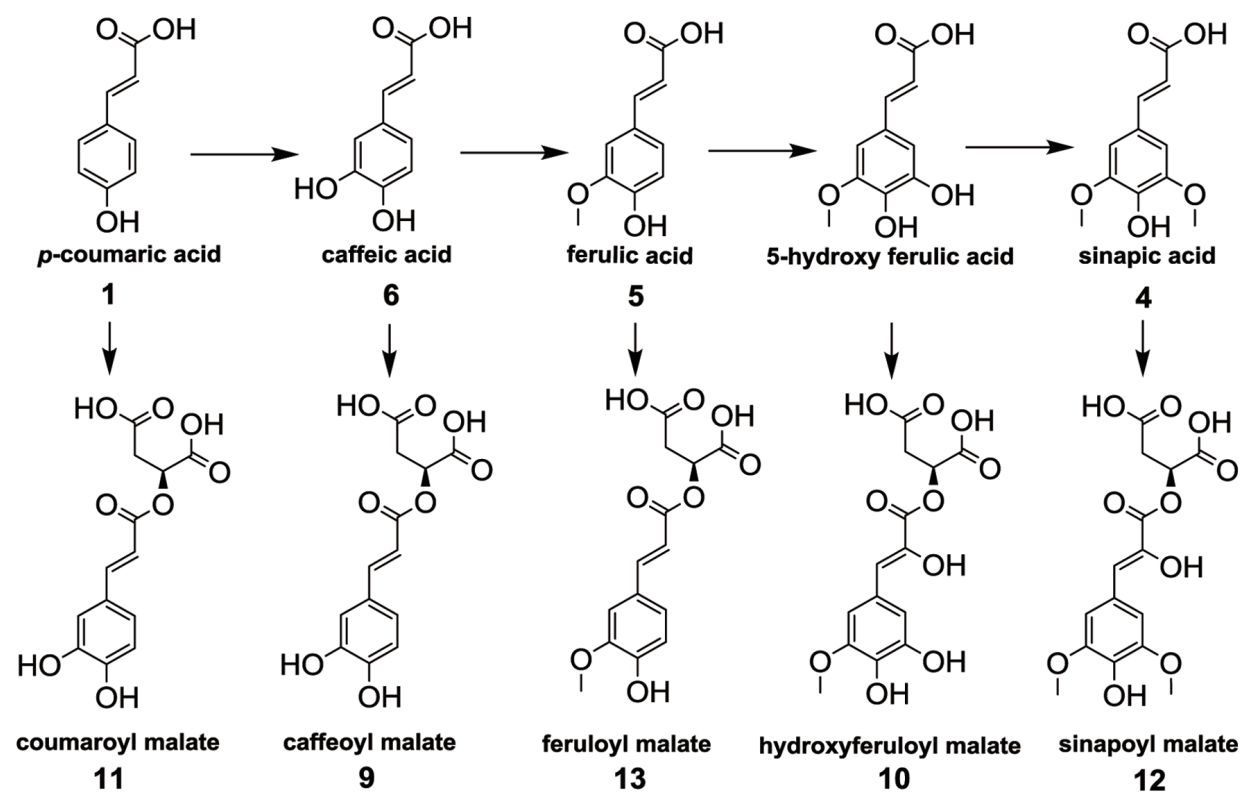

Figure 3. Hydroxycinnamic acids (HCA) (top) and malate esters of HCA (bottom) detected in Brassica microgreens under amber, blue and red LED.

al., 2014; Qu et al., 2020). Compound 21a/b with [M-H]- of m/z 753.2263 was tentatively identified as disinapoyl gentiobioside according to literature data with the major fragment of m/z 529.1561 (loss of 4) (Ferreres et al., 2008; Picchi et al., 2020). Compound $23 \mathrm{a} / \mathrm{b} / \mathrm{c}$ with $[\mathrm{M}-\mathrm{H}]^{-}$of $\mathrm{m} / \mathrm{z} 723.2151$ was tentatively identified as sinapoyl feruloyl gentiobioside in only radish (RR, RO) microgreens according to literature data on cabbage and $\mathrm{PC}$ and major fragments of m/z 499.1479 (loss of 4) and m/z 193.0509 (loss of gentiobiose and neutral 4) (Table 1) (Harbaum et al., 2007; Sousa et al., 2008).

\subsection{Flavonols and derivatives}

The MS analysis of all microgreen extracts indicated that the main flavonoids in Brassica vegetables were Qn and $\mathrm{Km}$ derivatives, and less of Iso, and most of them were ester-linked glycosides $(O-$ glycosides) or $O$-acylglycosides (Table 1) (Cartea et al., 2010; Sun et al., 2013).

Compound 24a with deprotonated molecular ion $[\mathrm{M}-\mathrm{H}]^{-}$of $\mathrm{m} / \mathrm{z}$ 609.1470 was tentatively identified as Km 3,7-diglucoside according to literature on other Brassica vegetables, with fragments of $\mathrm{m} / \mathrm{z}$ 447.0939 (loss of one glucose moiety, $162 \mathrm{amu}$ ) and m/z 285.0408 (Km, loss of the second glucose moiety) (Lin et al., 2011; Li et al., 2016). A lower peak area of $\mathrm{m} / \mathrm{z} 447.0939$ indicated the presence of the diglucoside moiety; thus, compound $24 \mathrm{~b}$ was tentatively identified as Km 3-glucosyl glucoside and 24c as Qn rhamnosyl glucoside based on the observed fragment of $\mathrm{m} / \mathrm{z} 447.0931$ (loss of glucosyl moiety) and m/z 301.0354 (Qn, loss of a glucosyl moiety) (Olsen et al., 2009; Sun et al., 2013). Compound 25a/b with [M$\mathrm{H}]^{-}$of $\mathrm{m} / \mathrm{z} 579.136$ was tentatively identified as Qn rhamnoside pentoside according to literature data and the observed fragments of m/z 447.0931 (loss of pentose, $132 \mathrm{amu}$ ) and m/z 301.0358 (Qn, loss of rhamnosyl unit, $146 \mathrm{amu}$ ) (Table 1) (Barros et al., 2011).

Compound 26 with pseudo-molecular ion $[\mathrm{M}-\mathrm{H}]^{-}$of $\mathrm{m} / \mathrm{z}$ 577.1563 was detected in radish microgreens (RR, RO) only, and was tentatively identified as $\mathrm{Km}$ 3,7-dirhamnoside with fragments $\mathrm{m} / \mathrm{z} 431.0986$ (neutral loss of one rhamnose, $146 \mathrm{amu}$ ) and $\mathrm{m} / \mathrm{z}$
285.0406 (Km, loss of second rhamnose) that indicated two rhamnose moieties in different positions on the aglycone (Harbaum et al., 2007; Negri et al., 2012). Structurally similar Km derivatives can also be found in turnip (B. rapa) and cabbage (B. oleracea) microgreens (Table 1) (Ferreres et al., 2008). Compound 27 with [M$\mathrm{H}]^{-}$of $\mathrm{m} / \mathrm{z} 563.1411$ was tentatively identified as Km rhamnosyl pentoside according to one study based on fragmentation of [M$\mathrm{H}]^{-}$to $\mathrm{m} / \mathrm{z} 431.1000$ (loss of pentose, $132 \mathrm{amu}$ ) and $\mathrm{m} / \mathrm{z} 285.0406$ (Km, loss of rhamnosyl moiety, $146 \mathrm{amu}$ ) (Barros et al., 2011). Deprotonated molecular ion [M-H] ${ }^{-}$of m/z 593.1513 and 933.2532 were tentatively identified as Km triglucoside rhamnoside $28 \mathrm{a} / \mathrm{b}$ and $\mathrm{Km}$ triglucoside glucoside 29 according to literature data and major fragments of $\mathrm{m} / \mathrm{z} 447.035$ and 771.2006 indicating the loss of rhamnosyl moiety (146 amu) and glucosyl moiety (162 amu), respectively. Both compounds $28 \mathrm{a} / \mathrm{b}$ and 29 also had fragment of $\mathrm{m} / \mathrm{z} 285.0406(\mathrm{Km})$ from the loss of the glucosyl (162 amu) and triglucosyl (648 amu) moiety, respectively (Table 1) (Gonzales et al., 2014; Onkokesung et al., 2014; Zhang et al., 2018).

Peaks 30-35 were acylglycosides of $\mathrm{Km}$. Compound $30 \mathrm{a} / \mathrm{b}$ with deprotonated molecular ion $[\mathrm{M}-\mathrm{H}]^{-}$of $\mathrm{m} / \mathrm{z} 963.2424$ was tentatively identified as Km hydroxyferuloyl diglucoside glucoside/Qn feruloyl diglucoside glucoside according to the literature data and based on fragments m/z 801.1872 and 609.1472 (loss of a glucosyl unit, $162 \mathrm{amu}$ ) and the feruloyl ion (192 amu). Additionally, fragments $\mathrm{m} / \mathrm{z} 284.0332$ (Km, loss of diglucoside moiety, $325 \mathrm{amu})$ and $\mathrm{m} / \mathrm{z}$ 300.021 (Qn) were observed (Table 1) (Li et al., 2018; Youssif et al., 2019). Compound $31 \mathrm{a} / \mathrm{b}$ and 32 with deprotonated molecular ion $[\mathrm{M}-\mathrm{H}]^{-}$of $\mathrm{m} / \mathrm{z} 1109.3011$ and m/z 947.2474 were tentatively identified as $\mathrm{Km}$ feruloyl trigulucoside glucoside and $\mathrm{Km}$ feruloyl diglucoside glucoside, respectively, based on similar fragmentation patterns, i.e., loss of the glucosyl and diglucosyl moieties, and the presence of the feruloyl and $\mathrm{Km}$ fragments (Schmidt et al., 2010; Li et al., 2018). Other Km derived cinnamic acid glucosides were tentatively identified as Km sinapoyl diglucoside glucoside $\left([\mathrm{M}-\mathrm{H}]^{-} \mathrm{m} / \mathrm{z}\right.$ 977.2584, 33), Km sinapoyl triglucoside glucoside $\left([\mathrm{M}-\mathrm{H}]^{-} \mathrm{m} / \mathrm{z} 1139.3110,34 \mathrm{a} / \mathrm{b}\right)$ and $\mathrm{Km}$ caffeoyl diglucoside glucoside $\left([\mathrm{M}-\mathrm{H}]^{-} \mathrm{m} / \mathrm{z}\right.$ 933.2314) based on similar fragmentation to the literature data (Table 1) (Schmidt et al., 2010; 
Li et al., 2018).

Qn glycosides were the most abundant flavonols in the microgreen samples. Compound $36 \mathrm{a} / \mathrm{b}$ with deprotonated molecular ion of $[\mathrm{M}-\mathrm{H}]^{-}$at $\mathrm{m} / \mathrm{z} 625.1414$ was tentatively identified as $\mathrm{Qn}$ 3,7-diglucoside/Qn 3-diglucoside according to the literature and fragments of m/z 463.0880 (loss of glucosyl moiety, $162 \mathrm{amu}$ ) and $\mathrm{m} / \mathrm{z} 301.0355$ (loss of second glucosyl) (Table 1) (Lin et al., 2011; Li et al., 2016). Compound 37 with deprotonated molecular ion of $[\mathrm{M}-\mathrm{H}]^{-}$at $\mathrm{m} / \mathrm{z} 593.1513$ was tentatively identified as Qn dirhamnoside according to one study with fragments of $\mathrm{m} / \mathrm{z} 446.0934$ (loss of first rhamnosyl unit, $146 \mathrm{amu}$ ) and m/z 301.0354 (Qn, loss of second rhamnosyl unit) (Barros et al., 2011). Compound 38 with deprotonated molecular ion of $[\mathrm{M}-\mathrm{H}]^{-}$at $\mathrm{m} / \mathrm{z} 949.248$ was tentatively identified as Qn triglucoside glucoside based on literature data in mustard greens, yu choy and 15 other Brassica vegetables and fragments of $\mathrm{m} / \mathrm{z} 787.1954$ (loss of first glucosyl moiety), m/z 462.0809 (loss of diglucoside, $325 \mathrm{amu}$ ) and $\mathrm{m} / \mathrm{z}$ 300.0278 (Qn, loss of second glucosyl) (Table 1) (Lin and Harnly, 2010).

Peaks 39-44 were Qn acylglycosides, except 43b which was a $\mathrm{Km}$ acylglycoside. Compound 39a/b with $[\mathrm{M}-\mathrm{H}]^{-}$at m/z 993.2535 was tentatively identified as Qn sinapoyl diglucoside glucoside/Qn sinapoyl triglucoside based literature data and fragments of $\mathrm{m} / \mathrm{z}$ 831.2026 (loss of glucosyl unit, $162 \mathrm{amu}$ ), m/z 300.0277 (Qn) and $\mathrm{m} / \mathrm{z} 462.0810$ (sinapoyl-glucoside) (Lin and Harnly, 2010; Gonzales et al., 2015). Compound 40a/b with $[\mathrm{M}-\mathrm{H}]^{-}$at $\mathrm{m} / \mathrm{z} 1155.3054$ was tentatively identified as Qn 3-sinapoyltriglucoside-7-glucoside according to the literature data in Brassica microgreens of other red mustards, pac choi, kale and mizunas other studies, and observed fragments of $\mathrm{m} / \mathrm{z} 993.2586$ (loss of glucosyl unit), $\mathrm{m} / \mathrm{z}$ 787.1922, m/z 462.0810 (Qn glucoside) and m/z 300.0275 (Qn, loss of glucosyl unit) (Table 1) (Llorach et al., 2003; Schmidt et al., 2010; Sun et al., 2013). Compound 41 with $[\mathrm{M}-\mathrm{H}]^{-}$at $\mathrm{m} / \mathrm{z}$ 933.2314 was tentatively identified as Qn coumaroyl diglucoside glucoside according to the literature and fragments of $\mathrm{m} / \mathrm{z}$ 787.1967 (loss of coumaroyl unit, $146 \mathrm{amu}$ ), m/z 624.400 (loss of $162 \mathrm{amu}$, glucosyl unit) and m/z 462.0805 (loss of glucosyl) and m/z 300.0272 (Qn) (Table 1) (Schmidt et al., 2010; Koley et al., 2020). A similar pattern was observed for $42 \mathrm{a} / \mathrm{b}$ which was tentatively identified as Qn hydroxyferuloyl diglucoside glucoside based on literature data and fragments $\mathrm{m} / \mathrm{z} 787.1943$ (loss of dehydrated dihydroferulic acid moiety, $192 \mathrm{amu}$ ), m/z 625.1415 (loss of glucosyl moiety) and the presence of Qn (m/z 300.0278) (Schmidt et al., 2010; Benayad et al. 2014). Compound 43a with pseudomolecular ion $[\mathrm{M}-\mathrm{H}]^{-}$of $\mathrm{m} / \mathrm{z} 1125.2957$ was tentatively identified as Qn 3-feruloyldiglucoside-7-glucoside according to literature data and fragments m/z 963.2440 (loss of glucosyl), m/z 787.1957 (subsequent loss of feruloyl group, $176 \mathrm{amu}$ ), m/z 463.0876 (loss of diglucoside, $324 \mathrm{amu}$ ) and presence of m/z $301.0355(\mathrm{Qn})$ (Table 1) (Li et al., 2018; Yang et al., 2018). An earlier eluting isomer $43 \mathrm{~b}$ with the same pseudo-molecular $[\mathrm{M}-\mathrm{H}]^{-}$was tentatively identified as $\mathrm{Km}$ 3-hydroxyferuloyl-diglucoside-7-diglucoside according to one study with fragments of $\mathrm{m} / \mathrm{z} 771.2006$ (loss of hydroxyferuloyl glucoside, $354 \mathrm{amu}$ ) and the presence of Km (Lin et al., 2011). Similarly, compound 44 with deprotonated molecular ion $[\mathrm{M}-\mathrm{H}]^{-} \mathrm{m} / \mathrm{z}$ 949.2274 was tentatively identified as Qn caffeoyl diglucoside glucoside according to the literature and by the losses of the glucosyl, diglucoside and caffeoyl moieties from $[\mathrm{M}-\mathrm{H}]^{-}$ to produce fragments of $\mathrm{m} / \mathrm{z} 787.1959,625.1420,462.0811$ and 300.0278 (Table 1) (Schmidt et al., 2010; Chen et al., 2019).

Compound 45 with deprotonated molecular ion of $[\mathrm{M}-\mathrm{H}]^{-}$at $\mathrm{m} / \mathrm{z} 623.1624$ was tentatively identified as Iso-glucoside rhamnoside according to previous reports in Brassica vegetables with fragments of m/z 477.1034 (loss of rhamnosyl, $146 \mathrm{amu}$ ) and m/z
315.0512 (Iso, loss of glucosyl, $162 \mathrm{amu}$ ) (Table 1) (Arimboor and Arumughan 2012; Sun et al., 2013; Chen et al., 2015). Compound 46 of $[\mathrm{M}-\mathrm{H}]^{-}$at $\mathrm{m} / \mathrm{z} 639.157$ was identified as Iso-3,7-diglucoside according to literature data and fragments $\mathrm{m} / \mathrm{z} 477.0142$ (loss of glucosyl moiety) and $\mathrm{m} / \mathrm{z} 315.0514$ (Iso, loss of second glucosyl) and (Table 1) (Lin et al., 2011; Li et al., 2016). One report identified the 3- and 7- monoglucosides of Iso that is common to Brassica vegetables; however, only trace amounts were observed in our RR and RO microgreens (Sun et al., 2013).

\subsection{Light effects on individual phenolic components in the microgreens}

The effects of seven different combined amber, blue and red LED ratios $(\%)$ on individual phenolic compounds in the microgreens were quantitatively analysed based on the ion counts of major peaks of the XIC of different microgreen samples grown under LED, and were compared to those under the basal (control) treatments (Table 2). Based on peak areas (ion counts), free phenolic acid contents in the microgreen samples were low (except in RO); most phenolic acids were present as derivatives or conjugated with other compounds (i.e. malates, glycosides). Phenolic acid glycosides predominated the pool of phenolics in the microgreens (except in RO). Flavonoid contents in the studied microgreens had significantly lower ion counts compared to the phenolic acids (Figure 2). The current study identified 23 flavonoids and their conjugates; the majority were various $\mathrm{Km}$ and Qn glycosides or acylglycosides and a small number of Iso glycosides (Table 1). Considering the low peak area data detected for free phenolic acids in addition to their very low abundance in Brassica, discussion will focus on compounds with peak ion counts $\geq 1.0 \mathrm{e}^{8}$ and the effects of the combined LED light on their accumulation as compared with control (\%) (Table 2). Data on other phenolic compounds and their changes from control are listed in Table S1. Generally, the highest ion counts $\left(\geq 1.0 \mathrm{e}^{8}\right)$ was observed for all HCA malates $9,10,11,12,13$, sinapoyl glucoside $22 \mathrm{a} / \mathrm{b} / \mathrm{c} / \mathrm{d}$ (MB only), feruloyl glucoside 19a/b (RO only) and Qn rhamnoside glucoside 24c (RO only).

In $B$. juncea microgreens (MB, MG and MSF) the predominate phenolics were malic acid esters of HCA with the highest peak intensity (ion counts). This agrees with literature reports for $B$. juncea which observed the predominating HCA to be the malate derivatives of sinapic, ferulic, hydroxyferulic and caffeic acids (Harbaum et al., 2008; Cartea et al., 2010). There was a significant decrease in 9, 10,12 and 13 in MB under most treatments, except under 12.02A:26.26B:61.14R resulting in their increase by $202 \%, 145 \%, 36 \%$ and $33 \%$, respectively (Table 2). In MB, sinapoyl glucoside $22 \mathrm{a} / \mathrm{b} / \mathrm{c} / \mathrm{d}$ was variably affected under the combined lighting treatments and was generally significantly decreased by $29-69 \%$. Contrasting responses under the lighting for MG were observed compared to MB, i.e., 9, 10, 11, 12 and 13 were overall significantly increased by $9.8-61.4 \%, 3.7-27.8 \%, 3.8-45.8 \%, 14$ $22.2 \%$ and $23.3 \%$, respectively, although 9 and 11 were decreased under $6.74 \mathrm{~A}: 22.68 \mathrm{~B}: 70.25 \mathrm{R}$ by $11.1 \%$ and $9.8 \%$, respectively (Table 2). Similarly, cinnamoyl malates $9,10,11,12$ and 13 in MSF were also significantly increased under most light treatments by 8.9-38.3\%, 5.7-46.4\%, 6.3-26.9\%, 4.7-17.4\% and $10.8-24.5 \%$, respectively, except for 10 and 13 under $14.53 \mathrm{~A}: 30.18 \mathrm{~B}: 51.82 \mathrm{R}$ and 9.51A:24.13B:65.91R (Table 2). Arabidopsis and other Brassica species accumulate sinapoyl malate in their leaves presumably as a protective measure against high energy UV radiation (Jin et al., 2000; Sullivan et al., 2021). This group of malates detected in $B$. juncea microgreens may have been accumulated under most 
Table 2. Effect of LED treatments on the quantity of major phenolic compounds (\% changes) in Brassica microgreens.

\begin{tabular}{|c|c|c|c|c|c|c|c|c|c|}
\hline \multirow{3}{*}{ Compound (\#) } & \multirow{3}{*}{ Light a } & \multicolumn{8}{|c|}{ Percent change (\%) ${ }^{b}$} \\
\hline & & \multicolumn{3}{|c|}{ Mizunas } & \multicolumn{2}{|c|}{ Radishes } & \multicolumn{3}{|c|}{ Mustards } \\
\hline & & MO & MR & PC & $\mathbf{R R}$ & RO & MSF & MB & MG \\
\hline \multirow[t]{7}{*}{ caffeoyl malate (9) } & 1 & NS & -17.2 & 21.2 & NS & -7.8 & 18.9 & 15.3 & 13.0 \\
\hline & 2 & 34.2 & 4.7 & 19.3 & 10.1 & -15.5 & NS & -52.6 & -11.1 \\
\hline & 3 & NS & NS & 18.6 & 27.3 & -27.3 & 27.6 & 201.8 & 39.5 \\
\hline & 4 & 9.0 & -17.9 & 6.5 & 22.5 & 15.5 & NS & -89.9 & 17.5 \\
\hline & 5 & 23.9 & -19.5 & 23.6 & -4.4 & -20.8 & 8.9 & -48.8 & 24.8 \\
\hline & 6 & NS & NS & -49.9 & 5.6 & -18.2 & 27.7 & -34.7 & 9.8 \\
\hline & 7 & -51.4 & -20.8 & 3.2 & 30.1 & -26.0 & 38.3 & -87.8 & 61.4 \\
\hline \multirow{7}{*}{$\begin{array}{l}\text { hydroxyferuloyl } \\
\text { malate (10) }\end{array}$} & 1 & 19.1 & -20.7 & 9.7 & 26.2 & 5.0 & 5.7 & NS & 7.1 \\
\hline & 2 & 42.0 & NS & 17.3 & 10.9 & -6.4 & NS & -54.5 & NS \\
\hline & 3 & 12.9 & NS & 15.1 & 72.2 & -24.4 & 34.4 & 145.2 & NS \\
\hline & 4 & 13.3 & -17.8 & NS & 33.8 & 44.4 & NS & -59.6 & NS \\
\hline & 5 & 28.9 & -22.1 & 11.5 & 16.5 & -9.5 & -7.0 & -61.0 & 27.8 \\
\hline & 6 & 10.8 & -8.3 & -45.8 & 71.2 & -16.2 & NS & -56.9 & 11.4 \\
\hline & 7 & -47.1 & -28.2 & 21.6 & 38.2 & -25.0 & 46.4 & -48.9 & 23.0 \\
\hline \multirow[t]{7}{*}{ coumaroyl malate (11) } & 1 & 7.2 & -10.5 & 7.5 & -5.9 & NS & 17.9 & NS & NS \\
\hline & 2 & 25.8 & -3.3 & 10.8 & 8.8 & NS & NS & NS & -9.8 \\
\hline & 3 & -8.9 & -6.3 & 11.2 & 53.6 & NS & 12.1 & NS & 22.6 \\
\hline & 4 & 11.2 & -14.7 & NS & 40.2 & 27.2 & NS & NS & NS \\
\hline & 5 & 16.6 & -18.2 & 16.3 & -5.1 & -30.2 & 6.3 & NS & NS \\
\hline & 6 & NS & -3.7 & -55.5 & 3.5 & -21.9 & 15.1 & NS & 7.4 \\
\hline & 7 & -60.1 & -20.5 & -6.2 & 64.6 & NS & 26.9 & NS & 45.8 \\
\hline \multirow[t]{7}{*}{ sinapoyl malate (12) } & 1 & 27.8 & -22.6 & 15.1 & 19.5 & 19.4 & 17.4 & -5.3 & NS \\
\hline & 2 & 41.9 & -4.9 & 20.4 & NS & NS & NS & -38.3 & 16.9 \\
\hline & 3 & NS & -3.9 & 19.3 & NS & -28.5 & 6.0 & 35.8 & NS \\
\hline & 4 & 15.1 & -18.2 & 5.0 & 14.2 & 29.9 & NS & -72.3 & 22.2 \\
\hline & 5 & 31.8 & -14.9 & 11.2 & NS & -9.3 & 4.7 & -36.3 & NS \\
\hline & 6 & NS & -13.6 & -42.7 & 18.8 & NS & NS & -32.6 & 14.0 \\
\hline & 7 & -48.8 & -39.1 & 4.9 & 11.7 & -30.4 & 9.5 & -35.8 & -10.1 \\
\hline \multirow[t]{7}{*}{ feruloyl malate (13) } & 1 & NS & -29.9 & NS & 6.0 & NS & 10.8 & -13.2 & NS \\
\hline & 2 & 21.3 & -13.8 & 9.5 & NS & -15.8 & -6.3 & -43.7 & NS \\
\hline & 3 & 7.1 & -2.1 & 22.3 & 31.0 & -26.6 & 16.7 & 33.0 & NS \\
\hline & 4 & NS & -21.0 & 24.8 & 21.3 & 12.9 & NS & -75.1 & NS \\
\hline & 5 & 11.2 & -22.5 & NS & NS & -23.4 & NS & -46.2 & 23.3 \\
\hline & 6 & -11.2 & -18.9 & -54.1 & NS & -20.6 & NS & -26.6 & NS \\
\hline & 7 & -52.3 & -37.4 & 19.3 & 31.0 & -31.7 & 24.5 & -63.8 & NS \\
\hline
\end{tabular}

aLED treatments: 1, 6.74A:22.68B:70.25R; 2, 9.51A:24.13B:65.91R; 3, 12.02A:26.26B:61.14R; 4,12.57A:44.31B:42.39R; 5, 14.53A:30.18B:51.82R; 6, 18.45A:33.51B:47.48R; 7, 39.46A:58.94B:0.57R. bSignificant changes (\%) from control ( $p<0.05)$ (4.73A:20.52B:74.36R); NS, not significant from control.

combined lighting regimes for similar reasons, or even under increasing blue light which is shown to be a source of high energy radiation in Brassica vegetables resulting in higher overall contents
(Li et al., 2013; Kopsell et al., 2015; Vaštakaite et al., 2015; Zheng et al., 2018; Li et al., 2019; Ying et al., 2020).

Among the $B$. rapa microgreens, the five cinnamoyl malates 
(9-13) in MO and PC were generally increased more significantly compared to MR. Under most treatments, 9, 10, 11, 12 and 13 in $\mathrm{MO}$ were significantly increased by $9-34.2 \%, 10.8-42 \%$, $7.2-25.8 \%, 15.1-41.9 \%$ and $7.1-21.3 \%$, respectively, except when treated under 39.46A:58.94B:0.57R leading to the significant decrease of $47.1-60.1 \%$ for these malates. Among the five, 11 and 13 also decreased under $12.02 \mathrm{~A}: 26.26 \mathrm{~B}: 61.14 \mathrm{R}$ and $18.45 \mathrm{~A}: 33.51 \mathrm{~B}: 47.48 \mathrm{R}$ by $8.9 \%$ and $11.2 \%$, respectively (Table 2). In PC, a similar response was observed for these five cinnamoyl malates significantly increasing under most lighting except when under 18.45A:33.51B:47.48R. Our findings agree with one study which also identified malate esters of HCA to predominate the pool of phenolics in several PC varieties (Harbaum et al., 2007). In contrast to $M O$ and PC, 9, 10, 11, 12 and 13 in MR were significantly decreased under most treatments by $17.2-20.8 \%$, $8.3-28.2 \%, 3.3-20.5 \%, 3.9-39.1 \%$ and $2.1-37.4 \%$ (Table 2). Only 9 was significantly increased in MR by $4.7 \%$.

Sinapic acid esters (e.g., sinapoyl malate and sinapoyl glucose) are important UV protectants in Brassica, and the genes involved in their biosynthesis in Arabidopsis are well documented (Fraser et al., 2007; Li et al., 2010; Shuab et al., 2016). The pathway for sinapoyl malate during biosynthesis in Brassica is well characterized biochemically and Arabidopsis genes encoding the enzymes upstream and downstream of UDP-glucosyltransferase (UGT) have been identified (Lim et al., 2001; Shuab et al., 2016). The precursor of sinapoyl malate is the glucose ester, thus modulation of the UGT enzyme involved in its formation may provide a better understanding for the link between sinapoyl malate and many other wavelengths under visible and UV light (Lim et al., 2001).

The $R$. sativus microgreens $\mathrm{RO}$ and RR differed in their response under the LED lightings in the five cinnamoyl malates 9-13. In RO, $9,10,11,12$ and 13 were significantly decreased under the lighting by $7.8-27.3 \%, 6.4-25 \%, 21.9-30.2 \%, 9.3-30.4 \%$ and $15.8-31.7 \%$, respectively, except under $12.57 \mathrm{~A}: 44.31 \mathrm{~B}: 42.39 \mathrm{R}$ which showed significant increase by $15.5 \%, 44.4 \%, 27.2 \%, 29.9 \%$ and $12.9 \%$, respectively (Table 2). In RR, on the other hand, 9, 10, 11, 12 and 13 , were overall significantly increased under most treatments by $5.6-30.1 \%, 10.9-71.2 \%, 3.5-64.6 \%, 11.7-19.5 \%$ and $21.3-31 \%$, respectively, and only 9 and 11 were significantly decreased under 14.53A:30.18B:51.82R by $4.4 \%$ and $5.1 \%$, respectively (Table 2 ). Compound $19 \mathrm{a} / \mathrm{b}$ in RO was also generally significantly increased by $3-60 \%$. Irrespective of the differences in the response under light in both radish microgreens, light-grown radish seedlings had higher activity of L-malate sinapoyltransferase, the enzyme catalyzing the transformation of sinapoyl glucose to sinapoyl malate, and low 1-(hydroxycinnamoyl)glucose-hydroxylcinnamoyl-transferase activities (Dahlbender and Strack 1986; Gräwe et al., 1992; Gutiérrez and Perez 2004). Further investigation into the genes controlling phenylpropanoid pathway enzymes and their response under LED would provide a more logical understanding of individual synthesis and opportunities for maximizing their content in microgreens.

\section{Conclusion}

Previously, we reported that the overall effect of various LED treatments of combined amber, red and blue lights on total phenolic content and antioxidant activities of the eight Brassica microgreens were highly species-dependent; some had high to moderately positive correlation with the LED dose, i.e., the increasing ratio of amber LED to blue and red LED, but some were not sensi- tive to the lighting (Alrifai et al., 2020). In the present study we focused on the profile and identification of individual phenolic compounds in these microgreens grown under the same LED lightings. By using LC-HRMS/MS-ESI, a total of 46 phenolics, including phenolic acids and flavonoids, were positively or tentatively identified. HCA derivatives were the predominant majority of the phenolics identified in the microgreens, followed by free phenolic acids and flavonol glycosides/acylglycosides. The overwhelming majority of the HCA derivatives were malate esters. In addition to species-specific responses, light quality played a large role in the profile and quantity of the phenolic compounds detected. Under combined red, blue and amber LED, the highest peak intensity by ion counts were malate esters of HCA observed in $R$. sativus microgreens, followed by $B$. juncea and B. rapa. HCA malates 9 , 10,12 and 13 in $\mathrm{MB}$ and 9-13 in MR and RO were decreased under most treatments, whereas all the five compounds (9-13) were overall increased under combined lighting in RR, MG, MO, PC, MSF. Additionally in MB, 9 and 10 were remarkably increased by $145 \%$ and $202 \%$ from the control, respectively, when grown under 12.02A:26.26B:61.14R

Results of the present study demonstrated that amber LED in combination with blue and red lights contributed to the altered phenolic profile and increase and/or decrease in quantity of certain phenolic compounds, particularly the HCA malates. The effect was also species-specific among the eight Brassica microgreens tested, suggesting that developing microgreens with high amount of certain phenolic compounds using the LED technology may be multifaceted. Also, the Brassica vegetables may contain other important bioactive phytochemicals such as carotenoids and glucosinolates, which may also contribute to the overall antioxidant or other health beneficial activities. Future studies should therefore investigate on the collective effect of LED lights on all phytochemical components and the molecular mechanisms modulating the synthesis of these bioactives. Since LED are an emerging modern technology for controlled environment agriculture, further investigation on this sub-group of vegetables under certain wavelengths and intensities will allow for production of highly nutritious microgreen vegetables. The literature is still scarce on studies investigating the underlying gene expression of the enzymes in biosynthetic pathways controlling various syntheses, and only a few to date have been studied in microgreens. Genes modulating phenylpropanoid pathway enzymes under LED, for example, would provide a logical understanding of individual synthesis response and opportunities for optimizing the nutritional and antioxidant value in microgreens.

\section{Acknowledgments}

This study was supported by the A-base funds of Agriculture \& Agri-Food Canada (AAFC). Project \#J-001328.001.04 and \#J002228.001.07.

\section{Conflict of interest}

The authors declare no competing financial interest.

\section{Supplementary material}

Table S1. Effect of LED treatments on the quantity of minor phenolic compounds (\% changes) in Brassica microgreens. 
References

Alrifai, O., Hao, X., Liu, R., Lu, Z., Marcone, M.F., and Tsao, R. (2021). LEDInduced Carotenoid Synthesis and Related Gene Expression in Brassica Microgreens. J. Agric. Food Chem. 69(16): 4674-4685.

Alrifai, O., Hao, X., Liu, R., Lu, Z., Marcone, M.F., and Tsao, R. (2020). Amber, red and blue LEDs modulate phenolic contents and antioxidant activities in eight Cruciferous microgreens. J. Food Bioact. 11: 95109.

Alrifai, O., Hao, X., Marcone, M.F., and Tsao, R. (2019). Current Review of the Modulatory Effects of LED Lights on Photosynthesis of Secondary Metabolites and Future Perspectives of Microgreen Vegetables. J. Agri. Food Chem. 67(22): 6075-6090.

Arimboor, R., and Arumughan, C. (2012). HPLC-DAD-MS/MS profiling of antioxidant flavonoid glycosides in sea buckthorn (Hippophae rhamnoides L.) seeds. Int. J. Food Sci. Nutr. 63(6): 730-738.

Barros, L., Dueñas, M., Ferreira, I.C.F.R., Maria Carvalho, A., and SantosBuelga, C. (2011). Use of HPLC-DAD-ESI/MS to profile phenolic compounds in edible wild greens from Portugal. Food Chem. 127(1): 169-173.

Benayad, Z., Gomez-Cordoves, C., and Es-Safi, N.E. (2014). Characterization of flavonoid glycosides from fenugreek (Trigonella foenumgraecum) crude seeds by HPLC-DAD-ESI/MS analysis. Int. J. Mol. Sci. 15(11): 20668-20685.

Blazics, B., Papp, I., and Kéry, Á. (2010). LC-MS Qualitative Analysis and Simultaneous Determination of Six Filipendula Salicylates with Two Standards. Chromatographia 71(1): 61-67.

Cartea, M.E., Francisco, M., Soengas, P., and Velasco, P. (2010). Phenolic compounds in Brassica vegetables. Molecules (Basel, Switzerland) 16(1): 251-280.

Chakraborty, D., and Mandal, S.M. (2013). Mass spectrometric detection of phenolic acids. In: Ramawat, K., and Mérillon, J.M. (Ed.). Natural Products. Springer, Berlin, Heidelberg, pp. 2047-2059.

Chen, X., Hanschen, F.S., Neugart, S., Schreiner, M., Vargas, S.A., Gutschmann, B., and Baldermann, S. (2019). Boiling and steaming induced changes in secondary metabolites in three different cultivars of pak choi (Brassica rapa subsp. chinensis). J. Food Compost. Anal. 82: 103232.

Chen, Y., Zhang, H., Liu, R., Mats, L., Zhu, H., Pauls, K.P., Deng, Z., and Tsao, R. (2019). Antioxidant and anti-inflammatory polyphenols and peptides of common bean (Phaseolus vulga L.) milk and yogurt in Caco-2 and HT-29 cell models. J. Funct. Foods 53: 125-135.

Chen, Y., Yu, H., Wu, H., Pan, Y., Wang, K., Jin, Y., and Zhang, C. (2015). Characterization and Quantification by LC-MS/MS of the Chemical Components of the Heating Products of the Flavonoids Extract in Pollen Typhae for Transformation Rule Exploration. Molecules 20(10): 18352-18366.

Dahlbender, B., and Strack, D. (1986). Purification and properties of 1-(hydroxycinnamoyl)-glucose:1-(hydroxycinnamoyl)-glucose hydroxycinnamoyltransferase from radish seedlings. Phytochemistry 25(5): 1043-1046.

Engels, C., Schieber, A., and Gänzle, M.G. (2012). Sinapic acid derivatives in defatted Oriental mustard (Brassica juncea L.) seed meal extracts using UHPLC-DAD-ESI-MS ${ }^{n}$ and identification of compounds with antibacterial activity. Eur. Food Res. Technol. 234(3): 535-542.

Ferreres, F., Valentao, P., Pereira, J.A., Bento, A., Noites, A., Seabra, R.M., and Andrade, P.B. (2008). HPLC-DAD-MS/MS-ESI screening of phenolic compounds in Pieris brassicae L. Reared on Brassica rapa var. rapa L. J. Agric. Food Chem. 56(3): 844-853.

Fraser, C.M., Thompson, M.G., Shirley, A.M., Ralph, J., Schoenherr, J.A., Sinlapadech, T., Hall, M.C., and Chapple, C. (2007). Related Arabidopsis serine carboxypeptidase-like sinapoylglucose acyltransferases display distinct but overlapping substrate specificities. Plant Physiol. 144(4): 1986-1999.

Gómez-Caravaca, A.M., López-Cobo, A., Verardo, V., Segura-Carretero, A., and Fernández-Gutiérrez, A. (2016). HPLC-DAD-q-TOF-MS as a powerful platform for the determination of phenolic and other polar compounds in the edible part of mango and its by-products (peel, seed, and seed husk). Electrophoresis 37(7-8): 1072-1084.

Gonzales, G.B., Raes, K., Vanhoutte, H., Coelus, S., Smagghe, G., and Van
Camp, J. (2015). Liquid chromatography-mass spectrometry coupled with multivariate analysis for the characterization and discrimination of extractable and nonextractable polyphenols and glucosinolates from red cabbage and Brussels sprout waste streams. J. Chromatogr A 1402: 60-70.

Gonzales, G.B., Smagghe, G., Raes, K., and Van Camp, J. (2014). Combined alkaline hydrolysis and ultrasound-assisted extraction for the release of nonextractable phenolics from cauliflower (Brassica oleracea var. botrytis) waste. J. Agric. Food Chem. 62(15): 3371-3376.

Grawe, W., Bachhuber, P., Mock, H.P., and Strack, D. (1992). Purification and characterization of sinapoylglucose:malate sinapoyltransferase from Raphanus sativus L. Planta 187(2): 236-241.

Gutiérrez, R.M.P., and Perez, R.L. (2004). Raphanus sativus (Radish): their chemistry and biology. The Scientific World JOURNAL 4: 811-837.

Harbaum, B., Hubbermann, E.M., Wolff, C., Herges, R., Zhu, Z., and Schwarz, K. (2007). Identification of Flavonoids and Hydroxycinnamic Acids in Pak Choi Varieties (Brassica campestris L. ssp. chinensis var. communis) by HPLC-ESI-MS $n$ and NMR and Their Quantification by HPLC-DAD. J. Agric. Food Chem. 55(20): 8251-8260.

Harbaum, B., Hubbermann, E.M., Zhu, Z., and Schwarz, K. (2008). Free and bound phenolic compounds in leaves of pak choi (Brassica campestris L. ssp. chinensis var. communis) and Chinese leaf mustard (Brassica juncea Coss). Food Chem. 110(4): 838-846.

Huanga, R.T., Lub, Y.F., StephenInbaraja, B., and Chena, B.H. (2015). Determination of phenolic acids and flavonoids in Rhinacanthus nasutus (L.) kurz by high-performance-liquid-chromatography with photodiode-array detection and tandem mass spectrometry. J. Funct. Foods 12: 498-508.

Jin, H., Cominelli, E., Bailey, P., Parr, A., Mehrtens, F., Jones, J., Tonelli, C., Weisshaar, B., and Martin, C. (2000). Transcriptional repression by AtMYB4 controls production of UV-protecting sunscreens in Arabidopsis. EMBO J. 19(22): 6150-6161.

Kim, J.K., and Park, S.U. (2021). Flavonoids for treatment of Alzheimer's disease: An up to date review. Excli. J 20: 495-502.

Kim, Y.J., Kim, Y.B., Li, X., Choi, S.R., Park, S., Park, J.S., Lim, Y.P., and Park, S.U. (2015). Accumulation of Phenylpropanoids by White, Blue, and Red Light Irradiation and Their Organ-Specific Distribution in Chinese Cabbage (Brassica rapa ssp. pekinensis). J. Agric. Food Chem. 63(30): 6772-6778.

Kim, Y.J., Kim, Y.B., Li, X., Choi, S.R., Park, S., Park, J.S., Lim, Y.P., and Park, S.U. (2020). High resolution LC-MS characterization of phenolic compounds and the evaluation of antioxidant properties of a tropical purple radish genotype. Arabian J. of Chem. 13(1): 1355-1366.

Kopsell, D.A., Sams, C.E., Robert, C., and Morrow, R.C. (2015). Blue Wavelengths from LED Lighting Increase Nutritionally Important Metabolites in Specialty Crops. HortScience 50(9): 1285.

Koley, T.K., Khan, Z., Oulkar, D., Singh, B.K., Maurya, A., Singh, B., and Banerjee, K. (2020). High resolution LC-MS characterization of phenolic compounds and the evaluation of antioxidant properties of a tropical purple radish genotype. Arabian J. Chem. 13(1): 1355-1366.

Kramberger, K., Barlic-Maganja, D., Bandelj, D., Baruca Arbeiter, A., Peeters, K., Miklavcic Visnjevec, A., and Jenko Praznikar, Z. (2020). HPLC-DAD-ESI-QTOF-MS Determination of Bioactive Compounds and Antioxidant Activity Comparison of the Hydroalcoholic and Water Extracts from Two Helichrysum italicum Species. Metabolites 10(10): 403.

Kyriacou, M.C., El-Nakhel, C., Pannico, A., Graziani, G., Soteriou, G.A., Giordano, M., Palladino, M., Ritieni, A., De Pascale, S., and Rouphael, Y. (2020). Phenolic Constitution, Phytochemical and Macronutrient Content in Three Species of Microgreens as Modulated by Natural Fiber and Synthetic Substrates. Antioxidants (Basel, Switzerland) 9(3): 252.

Kyriacou, M.C., El-Nakhel, C., Pannico, A., Graziani, G., Soteriou, G.A., Giordano, M., Zarrelli, A., Ritieni, A., De Pascale, S., and Rouphael, Y. (2019). Genotype-Specific Modulatory Effects of Select Spectral Bandwidths on the Nutritive and Phytochemical Composition of Microgreens. Front Plant. Sci. 10: 1501.

Lefevere, H., Bauters, L., and Gheysen, G. (2020). Salicylic Acid Biosynthesis in Plants. Front. Plant Sci. 11: 338.

Lehfeldt, C., Shirley, A.M., Meyer, K., Ruegger, M.O., Cusumano, J.C., Viitanen, P.V., Strack, D., and Chapple, C. (2000). Cloning of the SNG1 
gene of Arabidopsis reveals a role for a serine carboxypeptidase-like protein as an acyltransferase in secondary metabolism. Plant Cel 12(8): 1295-1306.

Li, H., Tang, C., and Xu, Z. (2013). The effects of different light qualities on rapeseed (Brassica napus L.) plantlet growth and morphogenesis in vitro. Sci. Horticult. 150: 117-124.

Li, J., Kuang, G., Chen, X., and Zeng, R. (2016). Identification of Chemical Composition of Leaves and Flowers from Paeonia rockii by UHPLC-QExactive Orbitrap HRMS. Molecules 21(7): 947.

Li, X., Bergelson, J., and Chapple, C. (2010). The ARABIDOPSIS accession Pna-10 is a naturally occurring sng1 deletion mutant. Mol. Plant 3(1) 91-100.

Li, Y., Zheng, Y., Liu, H., Zhang, Y., Hao, Y., Song, S., and Lei, B. (2019). Effect of supplemental blue light intensity on the growth and quality of Chinese kale. Horticulture, Environment, and Biotechnology 60(1): 49-57.

Li, Z., Lee, H.W., Liang, X., Liang, D., Wang, Q., Huang, D., and Ong, C.N. (2018). Profiling of Phenolic Compounds and Antioxidant Activity of 12 Cruciferous Vegetables. Molecules 23(5): 1139.

Lim, E.K., Li, Y., Parr, A., Jackson, R., Ashford, D.A., and Bowles, D.J. (2001). Identification of glucosyltransferase genes involved in sinapate metabolism and lignin synthesis in Arabidopsis. J. Biol. Chem. 276(6): 4344-4349.

Lin, L.Z., and Harnly, J.M. (2010). Phenolic component profiles of mustard greens, yu choy, and 15 other brassica vegetables. J. Agric. Food Chem. 58(11): 6850-6857.

Lin, L.Z., Sun, J., Chen, P., and Harnly, J. (2011). UHPLC-PDA-ESI/HRMS/ MS(n) analysis of anthocyanins, flavonol glycosides, and hydroxycinnamic acid derivatives in red mustard greens (Brassica juncea Coss variety). J. Agric. Food Chem. 59(22): 12059-12072.

Liu, L., Sonbol, F.M., Huot, B., Gu, Y., Withers, J., Mwimba, M., Yao, J., He, S.Y., and Dong, X. (2016). Salicylic acid receptors activate jasmonic acid signalling through a non-canonical pathway to promote effectortriggered immunity. Nat. Commun. 7(1): 13099.

Llorach, R., Gil-Izquierdo, A., Ferreres, F., and Tomas-Barberan, F.A. (2003). HPLC-DAD-MS/MS ESI characterization of unusual highly glycosylated acylated flavonoids from cauliflower (Brassica oleracea L. var. botrytis) agroindustrial byproducts. J. Agric. Food Chem. 51(13): 3895-3899.

Morreel, K., Saeys, Y., Dima, O., Lu, F., Van de Peer, Y., Vanholme, R., Ralph, J., Vanholme, B., and Boerjan, W. (2014). Systematic structural characterization of metabolites in Arabidopsis via candidate substrateproduct pair networks. Plant Cell 26(3): 929-945.

Negri, G., Santi, D., and Tabach, R. (2012). Chemical composition of hydroethanolic extracts from Siparuna guianensis, medicinal plant used as anxiolytics in Amazon region. Rev. Bras. Farmacogn. 22(5): 1024-1034.

Olsen, H., Aaby, K., and Borge, G.I.A. (2009). Characterization and Quantification of Flavonoids and Hydroxycinnamic Acids in Curly Kale (Brassica oleracea L. Convar. acephala Var. sabellica) by HPLC-DAD-ESI-MSn. J. Agric. Food Chem. 57(7): 2816-2825.

Onkokesung, N., Reichelt, M., van Doorn, A., Schuurink, R.C., van Loon, J.J., and Dicke, M. (2014). Modulation of flavonoid metabolites in Arabidopsis thaliana through overexpression of the MYB75 transcription factor: role of kaempferol-3,7-dirhamnoside in resistance to the specialist insect herbivore Pieris brassicae. J. Exp. Bot. 65(8): 2203-2217.

Oszmiański, J., Kolniak-Ostek, J., and Wojdyło, A. (2013). Application of ultra performance liquid chromatography-photodiode detector-quadrupole/time of flight-mass spectrometry (UPLC-PDA-Q/TOF-MS) method for the characterization of phenolic compounds of Lepidium sativum L. sprouts. Eur. Food Res. Tech. 236(4): 699-706.

Oulad El Majdoub, Y., Alibrando, F., Cacciola, F., Arena, K., Pagnotta, E., Matteo, R., Micalizzi, G., Dugo, L., Dugo, P., and Mondello, L. (2020). Chemical Characterization of Three Accessions of Brassica juncea $L$. Extracts from Different Plant Tissues. Molecules 25(22): 5421.

Picchi, V., Lo Scalzo, R., Tava, A., Doria, F., Argento, S., Toscano, S., Treccarichi, S., and Branca, F. (2020). Phytochemical Characterization and In Vitro Antioxidant Properties of Four Brassica Wild Species from Italy. Molecules 25(15): 220979424.

Ponte, L., Pavan, I., Mancini, M., da Silva, L., Morelli, A.P., Severino, M.B., Bezerra, R., and Simabuco, F.M. (2021). The Hallmarks of Flavonoids in Cancer. Molecules 26(7): 2029.
Qu, C., Yin, N., Chen, S., Wang, S., Chen, X., Zhao, H., Shen, S., Fu, F., Zhou, B., Xu, X., Liu, L., Lu, K., and Li, J. (2020). Comparative Analysis of the Metabolic Profiles of Yellow- versus Black-Seeded Rapeseed Using UPLC-HESI-MS/MS and Transcriptome Analysis. J. Agric. Food Chem. 68(10): 3033-3049.

Sarkar, A.K., Ghosh, D., Haldar, D., Sarkar, P., Gupta, B., Dastidar, S.G., and Pal, T.K. (2012). A rapid LC-ESI-MS/MS method for the quantitation of choline, an active metabolite of citicoline: Application to in vivo pharmacokinetic and bioequivalence study in Indian healthy male volunteers. J. Pharm. Biomed. Anal. 71: 144-147.

Schmidt, S., Zietz, M., Schreiner, M., Rohn, S., Kroh, L.W., and Krumbein, A. (2010). Identification of complex, naturally occurring flavonoid glycosides in kale (Brassica oleracea var. sabellica) by high-performance liquid chromatography diode-array detection/electrospray ionization multi-stage mass spectrometry. Rapid Commun. Mass. Spectrom. 24(14): 2009-2022

Shao, Y, Jiang, J., Ran, L., Lu, C., Wei, C., and Wang, Y, (2014). Analysis of Flavonoids and Hydroxycinnamic Acid Derivatives in Rapeseeds (Brassica napus L. var. napus) by HPLC-PDA-ESI(-)-MSn/HRMS. J. Agric. Food Chem. 62(13): 2935-2945.

Shuab, R., Lone, R., and Koul, K.K. (2016). Cinnamate and cinnamate derivatives in plants. Acta Physiologiae Plantarum 38(3): 64

Sinosaki, N.B.M., Tonin, A.P.P., Ribeiro, M.A.S., Poliseli, C.B., Roberto, S.B., Silveira, R., Visentainer, R.V., Santos, O.O., and Meurer, E.C. (2020). Structural Study of Phenolic Acids by Triple Quadrupole Mass Spectrometry with Electrospray lonization in Negative Mode and H/D Isotopic Exchange. J. Brazilian Chem. Soc. 31: 402-408.

Sousa, C., Valentao, P., Ferreres, F., Seabra, R.M., and Andrade, P.B. (2008). Tronchuda Cabbage (Brassica oleracea L. var. costata DC): Scavenger of Reactive Nitrogen Species. J. Agric. Food Chem. 56(11): 42054211.

Sullivan, M. (2009). A Novel Red Clover Hydroxycinnamoyl Transferase Has Enzymatic Activities Consistent with a Role in Phaselic Acid Biosynthesis. Plant Physiology 150(4): 1866-1879.

Sullivan, M.L., Green, H.A., and Verdonk, J.C. (2021). Engineering Alfalfa to Produce 2-O-Caffeoyl-L-Malate (Phaselic Acid) for Preventing Postharvest Protein Loss via Oxidation by Polyphenol Oxidase. Frontiers in Plant Science 11: 2152

Sun, J., Xiao, Z., Lin, L.Z., Lester, G.E., Wang, Q., Harnly, J.M., and Chen, P. (2013). Profiling polyphenols in five Brassica species microgreens by UHPLC-PDA-ESI/HRMS(n.). J. Agric. Food Chem. 61(46): 1096010970.

Tang, Y., Zhang, B., Li, X., Chen, P.X., Zhang, H., Liu, R., and Tsao, R. (2016). Bound Phenolics of Quinoa Seeds Released by Acid, Alkaline, and Enzymatic Treatments and Their Antioxidant and $\alpha$-Glucosidase and Pancreatic Lipase Inhibitory Effects. J. Agric. Food Chem. 64(8): 17121719.

Torras-Claveria, L., Jauregui, O., Codina, C., Tiburcio, A.F., Bastida, J., and Viladomat, F. (2012). Analysis of phenolic compounds by high-performance liquid chromatography coupled to electrospray ionization tandem mass spectrometry in senescent and water-stressed tobacco. Plant Sci. 182(1): 71-78.

Truchado, P., Vit, P., Heard, T.A., Tomas-Barberan, F.A., and Ferreres, F. (2015). Determination of interglycosidic linkages in O-glycosyl flavones by high-performance liquid chromatography/photodiodearray detection coupled to electrospray ionization ion trap mass spectrometry. Its application to Tetragonula carbonaria honey from Australia. Rapid Commun. Mass. Spectrom. 29(10): 948-954.

Vaštakaitè, V., Viršilè, A., Brazaitytè, A., Samuolienė, G., Jankauskienė, J., Sirtautas, R., Novičkovas, A., Dabašinskas, L., Sakalauskienè, S., Miliauskiene, J., and Duchovskis, P. (2015). The effect of blue light dosage on growth and antioxidant properties of microgreens. Sodininkystè ir daržininkystè 34(1-2): 25-35.

Wang, Y., Vorsa, N., Harrington, P.B., and Chen, P. (2018). Nontargeted Metabolomic Study on Variation of Phenolics in Different Cranberry Cultivars Using UPLC-IM-HRMS. J. Agric. Food Chem. 66(46): 1220612216.

Wu, Z.J., Ma, X.L., Fang, D.M., Qi, H.Y., Ren, W.J., and Zhang, G.L. (2009). Analysis of caffeic acid derivatives from Osmanthus yunnanensis using electrospray ionization quadrupole time-of-flight mass spectrometry. Eur. J. Mass. Spectrom. (Chichester) 15(3): 415-429. 
Yang, I., Jayaprakasha, G.K., and Patil, B. (2018). In vitro digestion with bile acids enhances the bioaccessibility of kale polyphenols. Food Funct 9(2): 1235-1244.

Ying, Q., Kong, Y., Jones-Baumgardt, C., and Zheng, Y. (2020). Responses of yield and appearance quality of four Brassicaceae microgreens to varied blue light proportion in red and blue light-emitting diodes lighting. Scientia Horticulturae 259: 108857.

Youssif, K.A., Haggag, E.G., Elshamy, A.M., Rabeh, M.A., Gabr, N.M., Seleem, A., Salem, M.A., Hussein, A.S., Krischke, M., Mueller, M.J., and Abdelmohsen, U.R. (2019). Anti-Alzheimer potential, metabolomic profiling and molecular docking of green synthesized silver nanoparticles of Lampranthus coccineus and Malephora lutea aqueous extracts. PLOS ONE 14(11): e0223781.

Zhang, H., and Tsao, R. (2016). Dietary polyphenols, oxidative stress and antioxidant and anti-inflammatory effects. Curr. Opin. Food Sci. 8: 33-42.

Zhang, K., Halitschke, R., Yin, C., Liu, C.J., and Gan, S.S. (2013). Salicylic acid 3-hydroxylase regulates Arabidopsis leaf longevity by mediating salicylic acid catabolism. Proc. Natl. Acad Sci. USA 110(36): 1480714812.

Zhang, Y., Xiong, H., Xu, X., Xue, X., Liu, M., Xu, S., Liu, H., Gao, Y., Zhang, H., and Li, X. (2018). Compounds Identification in Semen Cuscutae by Ultra-High-Performance Liquid Chromatography (UPLCS) Coupled to Electrospray Ionization Mass Spectrometry. Molecules 23(5): 1199.

Zheng, Y.J., Zhang, Y.T., Liu, H.C., Li, Y.M., Liu, Y.L., Hao, Y.W., and Lei, B.F. (2018). Supplemental blue light increases growth and quality of greenhouse pak choi depending on cultivar and supplemental light intensity. J. Integr. Agric. 17(10): 2245-2256. 